\title{
Risk Factors for Extra Pulmonary Tuberculosis in the Health District of Thies, Senegal
}

\author{
Kamadore Touré ${ }^{1, \text { * }}$, Diop Moustapha ${ }^{2}$, Ousmane Junior Dieng ${ }^{2}$, Mamadou Ndiaye ${ }^{1}$, \\ Diallo Abdoulaye ${ }^{1}$, Fatou Seck ${ }^{1}$, Madoky Maguatte Diop ${ }^{1}$, Adama Berthé ${ }^{1}$, \\ Pape Souleymane Touré ${ }^{1}$, Sylvie Audrey Diop ${ }^{1}$, Teri Lawson ${ }^{1}$, Bernard Marcel Diop ${ }^{1}$, \\ Mamadou Mourtala Ka ${ }^{1}$ \\ ${ }^{1}$ Department of Health Sciences, University of Thies, Thies, Senegal \\ ${ }^{2}$ Health District of Thies, Thies, Senegal
}

Email address:

tourekamadore@yahoo.ca (K. Touré), kamadore.toure@univ-thies.sn (K. Touré)

${ }^{*}$ Corresponding author

To cite this article:

Kamadore Touré, Diop Moustapha, Ousmane Junior Dieng, Mamadou Ndiaye, Diallo Abdoulaye, Fatou Seck, Madoky Maguatte Diop, Adama Berthé, Pape Souleymane Touré, Sylvie Audrey Diop, Teri Lawson, Bernard Marcel Diop, Mamadou Mourtala Ka. Risk Factors for Extra Pulmonary Tuberculosis in the Health District of Thies, Senegal. Central African Journal of Public Health.

Vol. 3, No. 5, 2017, pp. 68-72. doi: 10.11648/j.cajph.20170305.13

Received: June 11, 2017; Accepted: July 11, 2017; Published: September 26, 2017

\begin{abstract}
Tuberculosis (TB) is a national health priority in African countries particularly pulmonary form. But Extrapulmonary TB (EPTB) is increasing with less consideration for the governments. However, it has a negative impact in the social, economic and sanitary context. Few studies on the disease have been conducted in the African continent. The objective of this study was to estimate the incidence of Extrapulmonary TB in the Health District of Thies, a Senegalese province. Through a retrospective study, we collected data of all cases of TB admitted at the TB Division of the Health District of Thies, Senegal from January 2012 to December 2014. Sociodemographic characteristics of the patients, past medical history, lifestyles, the type of TB (pulmonary or extrapulmonary), the treatment regimen and the prognosis was evaluated. Uni, bi and multivariate analysis were done and results expressed with a 95\% confidence interval. On average, 824 patients with TB were included. They were mostly male (68.4\%), jobless $(62.9 \%)$, not married $(58.9 \%)$ with a mean age of 33.3 years $( \pm 14.3)$. They had in their past medical history a notion of TB contamination (30.1\%), BCG vaccination (96.5\%), hypertension $(4.6 \%)$, diabetes $(2.7 \%)$, HIV infection (1.7\%), smoking (11.5\%) and alcohol consumption (2.8\%). Hundred and Five patients $(12.7 \%$ with CI 95\%: $10.7 \%$ - 14.7\%) had EPTB of pleural (56.2\%), lymphatic (12.4\%), bone (9.5\%) and gastrointestinal (9.5\%) localization mainly. Age, notion of contact with patient, employment and HIV infection were associated independently to EPTB. It is important de take into consideration these results to strengthen primary prevention strategies.
\end{abstract}

Keywords: Extrapulmonary Tuberculosis, Tuberculosis, Risk Factors, Thies, Senegal

\section{Introduction}

Tuberculosis (TB) is an infectious disease, endemoepidemic and a health priority worldwide. With the occurrence of Human Immunodeficiency Virus (HIV) infection, TB is increasing either in developing than developed countries. ExtraPulmonary Tuberculosis (EPTB) characterized by the development of TB outside the lungs is also increasing in term of frequency worldwide [1-8]. However, clinical presentations are various and delaying the diagnosis. Some patients prefer living alone or staying at home without going to hospital for diagnosis and treatment because of stigma $[9,10]$. However, contact with TB patient alone sometimes can be sufficient to start TB treatment. All these factors could delay the treatment and compromise the vital and functional prognosis of EPTB patient [10]. This situation can compromise vital and functional prognosis of patients. Few studies have been conducted in Africa regarding ExtraPulmonary Tuberculosis. Several factors could explain this situation. However it is shared clinically by different specialties, it seems that it is underdiagnosed. Declaration of the disease could be missing. The other factor 
could be physician-based because of absence or delay in the screening of TB among patients. This could be related to lack of training, poor knowledge on the disease and lack of lab equipment in the African continent [1]. In another view, sometimes, treatment is proposed empirically based on clinical and radiological arguments. Studies conducted worldwide have identified several risk factors associated with the occurrence of EPTB: age [1, 2, 9], female sex [1, 11, 12], no vaccination [13], contact with TB patient [5, 12, 14], alcohol consumption $[11,15]$, employment $[13,16]$, diabetes [15] and HIV infection [1, 11] particularly. Senegal, like many Sub-Saharan African countries, is facing the TB epidemics. Thus, 10975 TB cases detected countrywide in 2008 and 11734 cases in 2009. Every year, according to the TB Program Experts, almost $70 \%$ of screened cases are expected of whom $80 \%$ should be treated to stop the transmission chain. The region of Thies is the third region where TB cases are prevalent (68\%) after Ziguinchor (72\%) and Dakar (79\%) [17]. To fight TB in general, decisionmakers need epidemiological studies for better management of dedicated program. The aim of this study was to identify the main risk factors associated to EPTB in the Health District of Thies, Senegal.

\section{Materials and Methods}

Through a retrospective study, we collected charts of all TB patients who were followed at the TB Program Division of the Health District of Thies, Senegal from January $1^{\text {st }}$ 20012 to December $31^{\text {st }} 20014$. The Health District of Thies covered a population of 632214 inhabitants. It had a health center and several health posts. The TB Program Division is located in the health center. It ensures the treatment of TB patients following the World Health Organization (WHO) Guidelines [18]. However, TB treatment is decentralized to health post for a better management of TB patients, they all have a medical/record at the TB Program Division of the health center of Thies. In the record, all required and useful informations are collected. The TB Program is run by a team coordinated by a Medical Doctor with nurse-assistant and community health workers trained for the task. During our study, all TB patients followed during the study period and who had finished their TB treatment were included in the study population. However, those who did not finish their treatment in 2014 were excluded. We collected data related to the sociodemographic characteristics of the patients (age, sex, employment, education, marital status), the past medical history (High Blood Pressure, Diabetes, HIV infection, BCG vaccination, Cancer, immunosuppressive treatment and others diseases), the lifestyle (smoking, alcohol), the notion of contact with TB patient, the localization of TB (Lung, Extrapulmonary $\mathrm{TB}$ ) and prognostic (recovering, relapse, loss of follow-up, death). Data processing was done using SPSS 20 package for Windows. Uni, bi and multivariate analysis were realized. So, we computed frequencies, mean with standard deviation first. Secondly, we compared percentage of EPTB according to sociodemographic characteristics of the patients, their past medical history, lifestyle to select independent variables to put in the final model for multivariate analysis. Odds ratios were computed and expressed with a $95 \%$ Confidence interval (CI).

\section{Results and Discussions}

\subsection{Results}

Eight hundred and twenty four patients were included during our study. They were mostly male $(68.4 \%)$, married (58.9\%), unemployed $(62.9 \%)$ with a mean age of 33.3 years $( \pm 14.3)$. Contact with TB patient $(69.9 \%)$, BCG vaccination (96.5\%), Hypertension (4.6\%), diabetes (2.7\%) and HIV infection $(1.7 \%)$ were the main past medical history. Smoking (11.5\%), alcohol consumption (2.8\%) and drug use $(0.60 \%)$ were the main lifestyle observed in our population (Table 1).

Table 1. Characteristics of the patients.

\begin{tabular}{lll}
\hline Variables & Frequency & Percentage (\%) \\
\hline Age & & \\
Mean: 33.3 years $( \pm 14.3,1-85$ years) & & \\
Median: 31 years & & \\
<19 years & 114 & 13.8 \\
20-39 years & 474 & 57.5 \\
40-59 years & 186 & 22.6 \\
60 years and plus & 50 & 6.1 \\
Male Sex & 564 & 68.4 \\
Employment (yes) & 306 & 37.4 \\
Married (yesi) & 339 & 41.1 \\
Past medical history & & \\
High Blood pressure & 38 & 4.6 \\
Diabetes & 22 & 2.7 \\
HIV infection & 14 & 1.7 \\
Contact with TB patient & 578 & 69.9 \\
Immunization with BCG & 795 & 96.5 \\
Lifestyles & & \\
Smoking & 95 & 11.5 \\
Alcohol & 23 & 2.8 \\
Drug use & 5 & 0.6 \\
\hline
\end{tabular}

During treatment, prognosis was characterized by remission in $72 \%$ of the patients while a lethality rate of $5.5 \%$ was observed. Among our population of patients, 105 had extrapulmonary tuberculosis [12.7\%; $\mathrm{IC}_{95 \%}$ : 10, 7-14, 7] of whom 99 had pure EPTB and 6 EPTB with lung TB. The mean number of cases was 35 per year. The main localization was predominantly pleural $(56.19 \%)$, lymph nodes $(12.40 \%)$, bone and gastrointestinal (9.52\%) (Table 2).

Table 2. Localization of ExtraPulmonary Tuberculosis $(N=105)$.

\begin{tabular}{lll}
\hline Localization of the EPTB & Frequency & Percentage (\%) \\
\hline Pleural & 59 & 56,2 \\
Lymph nodes & 13 & 12,4 \\
Bone-articulation & 10 & 9,5 \\
Digestive system & 10 & 9,5 \\
Miliary & 5 & 4,8 \\
Pericardia & 4 & 3,8 \\
Skin & 2 & 1,9 \\
Urogenital system & 1 & 0,9 \\
Nervous System & 1 & 0,9 \\
\hline
\end{tabular}


In the bivariate analysis, proportion of EPTB varied with age of the patients $(\mathrm{p} \leq .0 .002)$, contact with TB patient $(\mathrm{p} \leq .0 .046)$, employment $(\mathrm{p} \leq .0 .005)$ and HIV infection $(\mathrm{p} \leq .0 .002)$ (Table 3).

Table 3. Proportion of EPTB according to characteristics of the patients.

\begin{tabular}{|c|c|c|c|}
\hline Variables & Frequency & Percentage (\%) & P Value \\
\hline Age & & & $0.002 *$ \\
\hline$\leq 19$ years & 15 & 13.2 & \\
\hline $20-39$ years & 47 & 9.9 & \\
\hline $40-59$ years & 29 & 15.6 & \\
\hline 60 years and over & 14 & 28 & \\
\hline Sex & & & NS \\
\hline Male & 65 & 11.5 & \\
\hline Female & 40 & 13.4 & \\
\hline Employment & & & $0.046 *$ \\
\hline Yes & 52 & 10.8 & \\
\hline No & 53 & 15.5 & \\
\hline Married & & & NS \\
\hline Yes & 52 & 15.3 & \\
\hline No & 53 & 10.9 & \\
\hline \multicolumn{4}{|l|}{ Past Medical History } \\
\hline High Blood pressure & & & NS \\
\hline Yes & 3 & 7.9 & \\
\hline No & 102 & 13 & \\
\hline Diabetes & & & NS \\
\hline Yes & 1 & 4.5 & \\
\hline No & 104 & 13 & \\
\hline HIV Infection & & & $0.002 *$ \\
\hline Yes & 6 & 42.9 & \\
\hline No & 99 & 12.2 & \\
\hline Contact with TB patient & & & $0.004 *$ \\
\hline Yes & 86 & 14.9 & \\
\hline No & 19 & 7.7 & \\
\hline Immunization with BCG & & & NS \\
\hline Yes & 101 & 12.7 & \\
\hline No & 4 & 13.8 & \\
\hline \multicolumn{4}{|l|}{ Lifestyles } \\
\hline Smoking & & & NS \\
\hline Yes & 10 & 10.5 & \\
\hline No & 95 & 13 & \\
\hline Alcohol & & & NS \\
\hline Yes & 3 & 13 & \\
\hline No & 102 & 12.7 & \\
\hline
\end{tabular}

Younger age ' $1-19$ years $\left[\mathrm{OR}=3.74 ; \mathrm{CI}_{95 \%}: 1.55-7.02\right], 20$ 39 years $\left[\mathrm{OR}=3.58 ; \mathrm{CI}_{95 \%}: 1.75-7.20\right]$ ', notion of $\mathrm{TB}$ contamination $\left[\mathrm{OR}=2.22 ; \mathrm{CI}_{95 \%}: 1.30-3.78\right]$, absence of $\mathrm{HIV}$ infection $\left[\mathrm{OR}=0.19 ; \mathrm{CI}_{95 \%}: 0.06-0.57\right]$ and having an employment $\quad\left[\mathrm{OR}=0.52 ; \quad \mathrm{CI}_{95 \%}\right.$ : $\left.0.33-0.82\right] \quad$ were independently associated with Extra Pulmonary Tuberculosis at the multivariate logistic regression analysis (Table 4).

Table 4. Results of the multivariate analysis.

\begin{tabular}{llll}
\hline Variables & OR & 95\% IC & P value \\
\hline Age & & & \\
1-19 years & 3.74 & {$[1.55-9.02]$} & 0.003 \\
20-39 years & 3.55 & {$[1.75-7.20]$} & 0.000 \\
40-59 years & 2.02 & {$[0.95-4.28]$} & 0.66 \\
60 years and over & 1 & - & - \\
Employment & & & \\
Yes & 0.52 & {$[0.33-0.82]$} & 0.005 \\
No & - & - & - \\
Contact with TB & & & \\
patient & & & \\
\hline
\end{tabular}

\begin{tabular}{llll}
\hline Variables & OR & $\mathbf{9 5 \%}$ IC & P value \\
\hline Yes & 2.22 & {$[1.30-3.78]$} & 0.004 \\
No & 1 & - & - \\
HIV infection & & & \\
No & 0.19 & {$[0.06-0.57]$} & 0.003 \\
Yes & 1 & - & - \\
\hline
\end{tabular}

\subsection{Discussions}

Through a retrospective study, we have identified that younger age, employment, contact with TB patient and HIV infection were the main risk factors for ExtraPulmonary Tuberculosis in the Health District of Thies, Senegal. The age 0-19 years and 20-40 years were associated with a high risk for EPTB in our population of patients compared to 60 years and over. This means that the younger the patient is the higher the risk. This result confirms what was already found worldwide. The role of age as risk factors for EPTB has been highlighted by several studies worldwide. In Dakar, Senegal, a mean age of 36 years [19], 37 years [20] and 39 years [21] were found respectively with the age range of 30-44 years and 14-45 years being the most affected. In Benin [1] and Madagascar [22], similar results were almost observed with the age range of 25-34 years being the most affected. This was also the case in China [23], Saudi Arabia [24], Brazil [15], Germany [6] and USA [8]. According to Sandgren et al. [25], the European Union adult population in the range age of $25-44$ years $(36.7 \%)$ is the most affected by EPTB during a study among 167652 patients. The role of age could be explained by several factors. Young subjects are more exposed to be in contact with TB patient. They are more mobile and more at risk to meet TB patients in workplace, public transport and at home. Precarity with jobless and poverty are more frequent among youth exposing the young subjects to contact with Mycobacterium tuberculosis. The third factor could be related to HIV infection which is more common in young subjects exposing to TB. Employment was associated with EPTB in our study population. This result confirmed the role of employment in the occurrence of TB in general and EPTB in particular through several studies conducted worldwide. Indeed, in Africa, Oni et al. [13] showed that being employed was associated with a low risk [0.46; 95\% CI: 0.31-0.69] for the occurrence of tuberculosis. In Europe, same results were observed in Denmark [26] and in Croatia [7]. In the USA, unemployment was associated with EPTB [12, 16]. This is the case too in China [27] and Japan too [28]. Indeed, having a job provides income, improves standard of living, prevent from promiscuity and thus protects against tuberculosis. These results confirm the hypothesis that tuberculosis is usually a disease of poverty. However, among the jobs, those related to the health environment were the most at risk. Indeed, according to some authors, health care professionals are those who are at greater risk of developing tuberculosis. This could be related to the fact that health professionals are more in contact with patients and also pathological products (sputum, cerebrospinal fluid, bones, pleural liquid and so on) than no health professionals. Contact with TB patient was associated 
with the occurrence with EPTB with a risk of 2.22 [95\% CI: 1.30 - 3.78]. This result confirms what has been observed elsewhere in the world. The same risk was observed during studies conducted in Africa especially in Zambia [14], Malawi [29], Ethiopia [5] and Gambia [30]. In the USA, the risk was 1.7 [11]. In Europe, it was 2.19 in Croatia [7] and 2.06 in Georgia [31]. In Asia, same results were observed in China [27] and Japan [28]. For some authors, the risk is higher among health personnel. In China [27], the risk among this group was 2.47 while in Japan it was 25 among laboratory technicians [28]. These results confirm that contact with TB patient is an important risk factor for the occurrence of tuberculosis in general and EPTB is not an exception. A person with untreated pulmonary tuberculosis with positive sputum exam can contaminate his entourage with Pflügge droplets when coughing or sneezing. This is related to the fact that the main route of TB transmission in human being is airborne. However, the notion of TB patient contact remains underestimated, especially in Africa where TB patients are not so isolated even during hospital admission. With the visits of the family during hospitalization, contamination remains common. This is the case also in public transportation, working place and public stations where promiscuity is also common. Otherwise, some TB patients hide their illness because of stigmatization which increases the risk of TB contamination. This is another reason to search for $\mathrm{TB}$ contact in case of ExtraPulmonary Tuberculosis observed in our daily consultation. Absence of past medical history of HIV infection was associated with the occurrence of Extrapulmonary Tuberculosis with a risk of 0.19. HIV infection is a significant risk factor for EPT as observed during studies conducted worldwide. The association HIV and Tuberculosis is common so that it is recommended to screen for HIV whenever TB occurs and vice versa. However in Senegal, few studies focused on the association between HIV infection and Extrapulmonary Tuberculosis $[19,25]$. Otherwise, this association is almost common in Zambia [14], Ethiopia [21], South Africa [32] and Burkina Faso [33] in the African continent where HIV infection is very frequent. In Europe, the same risk was observed in Portugal [24], France [34] and Spain [35]. This is the case too in USA [11, 36, 37] and Brazil [15] in the American continent. In Thailand, Kingkaew et al. [38] during a study on the epidemiology and risk factors for death followed 308 patients presenting Extrapulmonary Tuberculosis over 1 year. HIV infection was associated with EPTB tuberculosis with a risk of 1.70. These results confirm the role of HIV infection on the occurrence of ЕРTB worldwide. In fact, HIV infection leads to immunosuppression. This situation promotes the reactivation of quiescent mycobacterial bacilli, their multiplication and also the destruction of immune/defense mechanisms. Thus, the body become vulnerable and more easily compromised leading to $\mathrm{TB}$ infection. It is important to screen for $\mathrm{TB}$ whatever the localization when a patient is HIV positive through sputum test or other immunological tests like Genexpert or Quantiferon. By the way, whenever TB infection is suspected, it is recommended to start antimycobacterial treatment to tackle infection before its spread which can compromise the functional and vital prognosis. However, it presented some limits related to many factors: identification of the cases which is sometimes based on presumptive signs and symptoms leading to misclassification of cases and under or upper estimation the cases. The second factor is related to the identification of risk factors which could have been missing for some patients.

\section{Conclusion}

This study has helped to identify risk factors associated with ExtraPulmonary Tuberculosis among TB patients followed at the TB Program Division of the Health District of Thies, Senegal. Younger age, employment, contact with TB patient and HIV infection were independently associated with ExtraPulmonary Tuberculosis in the Health District of Thies, Thies, Senegal. It is important to take into consideration these results to strengthen preventive strategies to tackle this endemic disease in the Health District of Thies, Senegal.

\section{References}

[1] S Ade, AD Harries, A Trebucq, et al. National Profile And Treatment Outcomes Of Patients with Extrapulmonary Tuberculosis in Benin. PLoS One, 9(4): e95603, 2014.

[2] D Aerts, R Jobim. The epidemiological profile of tuberculosis in southern Brazil in times of AIDS. Int J Tuberc Lung Dis, 8 (6), pp 785-791, 2004.

[3] S Al-Hajoj, M Shoukri, Z Memish, et al. Exploring The Socio-Demographic and clinical features of Extrapulmonary Tuberculosis in Saudi Arabia. Plos One, 10 (2), e0101667, 2015.

[4] S Berg, E Schelling, F Hailu, et al. Investigation of the high rates of extrapulmonary tuberculosis in Ethiopia reveals no single driving factor and minimal evidence for zoonotic transmission of Mycobacterium bovis infection. BMC Infect Dis, 15, p112, 2015.

[5] PT Ephrem, B Mengiste, F Mesfin, W Godana. Determinants of active pulmonary tuberculosis in Ambo Hospital, West Ethiopia. Afr J Prim Health Care Fam Med. 2015; 7(1), 608-8, 2015.

[6] M Forssbohm, M Zwahlen, R Loddenkemper, HI Rieder. Demographic characteristics of patients with extrapulmonary tuberculosis in Germany. Eur Respir J, 31(1), pp 99-105, 2008 .

[7] A Jurcev-Savicevic, R Mulic, B Ban, K Kozul, L Bacun-Ivcek, $\mathrm{J}$ Valic, et al. Risk factors for pulmonary tuberculosis in Croatia: a matched case-control study. BMC Public Health, 13, pp 991-998, 2013.

[8] IL Leeds, MJ Magee, EV Kurbatova, C Delrio, HM Blumberg, MK Leonard, et al. Site of extrapulmonary tuberculosis is associated with HIV infection. Clin Infect Dis, 55 (1), pp 75$81,2012$. 
[9] Coalition Antituberculeuse Pour L'assistance Technique. Standards internationaux pour le traitement de la tuberculose (SITT). La Haye: Coalition antituberculeuse pour l'assistance technique, 2006.

[10] LV Cowie, JW Sharpe (1997). Extra-pulmonary tuberculosis: a high frequency in the absence of HIV infection. Int $\mathrm{J}$ Tuberc Lung Dis, 1 (2), pp 159-162, 1997.

[11] CT Fiske, MR Griffin, H Erin, J Warkentin, K Lisa K, PG Arbogast, et al. Black race, sex, and extrapulmonary tuberculosis risk: an observational study. BMC Infect Dis, 10:16, 2010.

[12] HM Peto, RH Pratt, TA Harrington, PA Lobue, LR Armstrong. Epidemiology of extrapulmonary tuberculosis in the United States, 1993-2006. Clin Infect Dis, 49 (9), pp 1350-1357, 2009.

[13] T Oni, HP Gideon, N Bangani, R Tsekela, R Seldon, et al. Smoking, BCG and Employment and the Risk of Tuberculosis Infection in HIV-Infected Persons in South Africa. Plos One, 7 (10): e47072, 2012.

[14] D Boccia, J Hargreaves, BI De Stavola, K Fielding, A Schaap, $\mathrm{P}$ Godfrey-Faussett $\mathrm{P}$, et al. The association between household socioeconomic position and prevalent tuberculosis in Zambia: a case-control study. Plos One, 6(6):e20824, 2011.

[15] T Gomes, B Reis-Santos, A Bertolde, LJ Johnson, LW Riley, LE Maciel. Epidemiology of extrapulmonary tuberculosis in Brazil: a hierarchical model. BMC Infectious Diseases, 14, 9, 2014.

[16] X Wang, Z Yang, Y Fu, G Zhang, X Wang, et al. Insight to the Epidemiology and Risk Factors of Extrapulmonary Tuberculosis in Tianjin, China during 2006-2011. Plos One, 9(12): pp e112213, 2014.

[17] Programme National De Lutte Contre La Tuberculose (Pnt). Rapport annuel de 2013. Dakar: PNT-Sénégal; 2013.

[18] C Dye. Global epidemiology of tuberculosis. Lancet, 37 (9514), pp 938-940, 2006.

[19] MB Diallo. La Tuberculose Extrapulmonaire Au Cours De L'infection A VIH; aspects épidémiologiques, cliniques et évolutifs: à propos de 247 cas colligés à la clinique des Maladies Infectieuses de Fann. Thèse Médecine. Dakar, Université Cheikh Anta Diop; N², 2006.

[20] M Soumare, M Seydi, I Sow, S Diop, C Senghor, C Ndour, et al. Tuberculose et SIDA à Dakar: étude rétrospective à propos de 630 cas. Rev CAMES A, 6, pp 97-100. 2008.

[21] BG Sylla. La tuberculose extrapulmonaire. Thèse Médecine, Dakar: Université Cheikh Anta Diop; 2004, n 4.

[22] RV Razanamparany, D Menard, G Auregan, B Gicquel, S Chanteau. Extrapulmonary and pulmonary tuberculosis in Antananarivo (Madagascar): high clustering rate in female patients. J Clin Microbiol, 40 (11): pp 3964-3969, 2002.

[23] K Noertjojo, CM Tam, SL Chan, MM Chan-Yeung. Extrapulmonary and pulmonary tuberculosis in Hong Kong. Int J Tuberc Lung Dis, 6(10), pp 879-886, 2002.

[24] AH Sahal, M Shoukri, Z Memish, AH Raafat, A Fahad, V Bright. Exploring the Sociodemographic and Clinical Features of Extrapulmonary Tuberculosis in Saudi Arabia. Plos One, 3, pp 11, 2015.
[25] A Sandgren, V Hollo, MJ Van Der Werf. Extrapulmonary tuberculosis in the European Union and European Economic Area, 2002 to 2011. Euro Surveill, 18(12): pp: 20431, 2013.

[26] K Ladefoged, T Rendal, T Skifte, M Andersson, B Soborg, A Koch. Risk factors for tuberculosis in Greenland: case-control study. Int J Tuberc Lung Dis, 15 (1), pp 44-49, 2009.

[27] X Zhang, K Jia, F Liu, L Pan, A Xing, et al. Prevalence and Risk Factors for Latent Tuberculosis Infection among Health Care Workers in China: A Cross-Sectional Study. Plos One, 8 (6), pp e66412, 2013.

[28] T Usui, K Yamanaka, H Nomura, S Tokudome. Elevated Risk of Tuberculosis by Occupation with Special Reference to Health Care Workers. J Epidemiol, 10, pp 1-6, 2000.

[29] A Odone, AC Crampin, V Mwinuka, S Malema, JN Mwaungulu, L Munthali, et al. Association between socioeconomic position and tuberculosis in a large populationbased study in rural Malawi. Plos One, 8 (10):e77740, 2013.

[30] C Lienhardt, J Sillah, K Fielding, S Donkor, K Manneh, D Warndorff, et al. Risk factors for tuberculosis infection in children in contact with infectious tuberculosis cases in the Gambia, West Africa. Pediatrics, 111 (5), pp e608-e614, 2003.

[31] V Mirtskhulava, R Kempker, KL Shields, MK Leonard, T Tsertsvadze, C Del Rio, et al. Prevalence and Risk Factors for Latent Tuberculosis Infection among Health-care Workers in the Country of Georgia. Int J Tuberc Lung Dis, 12 (5), pp 513-519, 2008.

[32] AS Karstaedt, M Bolhaar. Tuberculosis in older adults in Soweto, South Africa. Int J Tuberc Lung Dis, 18 (10), pp 1220-1222, 2014.

[33] JE Malkin, T Prazuck, F Simonnet, M Yameogo, A Rochereau, $\mathrm{J}$ Ayeroue, D Masson, C Lafaix. Tuberculosis and Human Immunodeficiency virus infection in West Burkina Faso; clinical presentation and clinical evolution. Int $\mathbf{J}$ Tuber Lung Dis, 1 (1), pp 68-74, 1997.

[34] JP Lanoix, T Guimard, N Ettahar, A Grannec, C Flateau, C Chapuzet, et al. Risk factors for prolonged treatment of lymph node tuberculosis. Int J Tuberc Lung Dis, 16 (3), pp 373-375, 2012.

[35] GP Olalla, MA Martinez-Gonzalez, JA Cayla, JM Jansa, B Iglesias, R Guerrero, et al. Influence of highly active antiretroviral therapy (HAART) on the natural history of extrapulmonary tuberculosis in HIV patients. Int $\mathbf{J}$ Tuberc Lung Dis, 6 (12), pp 1051-1057, 2002.

[36] OY Gonzalez, G Adams, LD Teeter, TT Bui, JM Musser, MA Graviss. Extra-pulmonary manifestations in a large metropolitan area with a low incidence of tuberculosis. Int $\mathrm{J}$ Tuberc Lung Dis, 7(12), pp1178-1185, 2003.

[37] A Kwara, S Roahen-Harrison, E Prystowsky, P Kissinger, R Adams, J Mathison, et al. Manifestations and outcome of extra-pulmonary tuberculosis: impact of Human Immunodeficiency Virus co-infection. Int J Tuberc Lung Dis, 9 (5), pp 485-493, 2005.

[38] N Kingkaew, B Sangtong, W Amnuaiphon, J Jongpaibulpatana, W Mankatittham, S Akksilp, et al. HIVassociated extrapulmonary tuberculosis in Thailand: epidemiology and risk factors for death. Int J Tuberc Dis, 13 (6), pp 722-729, 2009. 